\title{
MIRADA DE HOMBRE EN BOCA DE MUJER: LA RETÓRICA FEMENINA DE LAS CARTAS RECOMENDATORIAS TEXEDIANAS ${ }^{1}$
}

\author{
M. Josefa Navarro Gala \\ Universidad del País Vasco / Euskal Herriko Unibertsitatea \\ galagla@hotmail.com
}

\section{RESUMEN}

El examen de los tópicos y argumentos de las 71 cartas de recomendación que contienen las ediciones de 1547, 1549, 1552 y 1553 del Libro de cartas mensajeras de Gaspar de Texeda ha permitido cotejar las realizaciones retóricas atribuidas a hombres y mujeres. Las cartas femeninas estudiadas adoptan todavía los usos clásicos reformulados por el ars dictaminis medieval, mostrando una elaboración pausada y reflexiva del artificio retórico, donde prima la singularidad y la variedad elocutiva. Es ésta, en cambio, una práctica demodée e infrecuente en las cartas de los hombres, quienes restringen utilitariamente su hacer epistolar a las observaciones secretariales vigentes en la época, formal y conceptualmente más rígidas y estereotipadas.

PAlABRAS ClAVE: cartas de recomendación, mujeres, retórica epistolar, formularios, Gaspar de Texeda.

\section{RÉSUMÉ}

L'examen des topiques et des arguments des 71 lettres de recommandation contenant des éditions de 1547, 1549, 1552 et 1553 du Libro de cartas mensajeras de Gaspar

\footnotetext{
1 Este trabajo se ha realizado en el marco del Proyecto de Investigación «La retórica de género en manuales educativos de los siglos XV y XVI», subvencionado por la Universidad del País Vasco (UPV05/51).
} 
de Texeda a permis comparer les réalisations rhétoriques attribuées aux hommes et aux femmes. Les femmes de lettres étudiées adoptent encore les applications classiques reformulées par l'ars dictaminis médiéval, montrant un développement lent et réfléchi de la rhétorique, où la priorité est l'unicité et la variété élocutive. C'est, cependant, une pratique démodée et peu fréquente dans les lettres d'hommes, qui limitent leur correspondance aux observations utilitaires des secrétaires en vigueur à l'époque, formellement et conceptuellement plus rigides et stéréotypées.

MoTS-CLÉs: lettres de recommandation, femmes, rhétorique épistolaire, formulaires, Gaspar de Texeda.

Es bien conocida la tradición epistolográfica que postula la superioridad de la escritura de las mujeres, arguyendo criterios tan dudosos -máxime en el tan reglamentado género epistolar- como la dulzura, la espontaneidad o la irreflexión². Ya en un trabajo anterior (Navarro, 2011), aludimos sucintamente a tales prejuicios valorativos, repetidos con fruición desde el siglo XVII hasta hoy (Torras, 2001: 13-15 y 49-84 y Nies, 1978). Rastreando las observaciones estilísticas espigadas en los modelos de cartas del temprano muestrario texediano, pudimos constatar que la «suavíssima dulçura de la lengua» (Texeda, 1553: f. LXXIX r) y la «sincera facilidad y ligereza» (Texeda, 1553: f. CIII v) compositivas eran, en efecto, distintivos frecuentemente aplicados por el autor a la epistolografía femenina. Sin embargo, quedaba por dirimir si la realización retórica de las cartas de mujeres incluidas en el formulario evidenciaba de facto tal dulzura y espontaneidad y, de ser así, cuál era la operatividad textual, y por ende la apreciación valorativa, atribuida por el autor a estas estrategias discursivas consideradas intrínsicamente femeninas. El análisis propuesto en estas páginas se centra, por tanto, en el examen de los tópicos y argumentos de un tipo específico de cartas, las de recomendación, al objeto de cotejar en ellas las realizaciones retóricas de uno y otro sexo.

\section{Mirada DE hombre En bOCA DE MUJer: LA CARTA FingidA}

El Primero Libro/ de cartas mensageras, en estilo/ Cortesano, para diuersos fines y/ propósitos con los títulos y/ cortesías que se vsan en to/dos los estados (Valladolid, Sebastián Martínez, 1553) de Gaspar de Texeda nace en medio de un complejo y tumultuoso panorama epistolográfico, cuyo principal rasgo es el hibridismo ${ }^{3}$. Los tratados doctrinales latinos dan paso a los manuales epistolares vernáculos, afianzando y difundiendo determinados modelos expresivos, que son ávidamente consumidos por un público cada vez más amplio (Chartier, 1993: 284-314 y Dûchene, 1978: 978). Simultáneamente, la elocución y la destreza expresiva se convierten en exponentes de prestigio social y en aspiración de todo aquel que desee mostrar su corrección y su buen gusto ${ }^{4}$.

\footnotetext{
2 Piénsese en el abad Cotin, La Bruyère, Lanson, Eugenio de Ochoa o el propio Pedro Salinas, entre otros.

3 Conviven tendencias epistolográficas diversas e incluso opuestas: la carta elocucionista de Ramus, la ciceroniana, la retórica erasmiana y la clásica-familiar, propugnada por Vives. Al respecto, véanse Martín Baños (2005a: 305-418 y 457-486 y 2005b: 15-30); Ward (1999); Rice (1999: 415-416); Monfasani (1999) y López Grigera (1994: 51-56; 69-93 y 108-111), entre otros.

4 En gran medida gracias a la divulgación de El Cortesano de Castiglione (1528). Sobre la incidencia de esta obra en la tratadística epistolar, pueden consultarse Martín Baños (2005a: 475-479), Castillo Gómez (2002: 89), Marín Pina (1988: 21) y Lafaye (1984: 248).
} 
El Libro de Texeda es una obra clave para el estudio de la epistolografía, no sólo porque se trata del primer formulario en castellano ${ }^{5}$ y porque sus sucesivas reediciones $(1547,1549,1553)$ constatan que fue una obra muy leída durante los años centrales del XVI, sino también porque la gran cantidad y multiplicidad de las cartas-modelo que contiene, la variedad de asuntos abordados en ellas, la diversa extracción social de los corresponsales implicados y la desigual calidad compositiva de sus ejemplos hacen de él uno de los mejores y más completos tratados impresos en Europa (Guillén, 1998: 182) . Desde la perspectiva de los estudios de género es este, además, un repertorio ciertamente atípico porque, a diferencia de los formularios con los que compite, da cabida entre sus páginas a una elevada y variopinta representación de cartas femeninas ${ }^{7}$, que en alguna de las ediciones suponen más de la tercera parte del Libro $^{8}$.

Puesto que nuestro objetivo es cotejar las estrategias y modos de la retórica epistolar atribuidos a hombres y a mujeres, la primera cuestión que hemos de plantearnos ante este tipo de tratado es, sin duda, la naturaleza de las cartas que lo constituyen: ¿son cartas reales o cartas inventadas ex profeso por el autor? Sabido es que las artes medievales combinaban con frecuencia cartas reales y cartas elaboradas por el preceptista específicamente para la ocasión; de manera que parece lógico postular un procedimiento similar para los formularios quinientistas. Así, por ejemplo, en el Libro de Texeda, la carta excusatoria con «que respondió el auctor a un amigo suyo que le impor/tunava que dexasse la corte para yr a ser secretario de un gran/ señor» (Texeda, 1547, 38: f. C v; 1549, 62, ff. E r-v) o la carta «Graciosa de un cortesano a otro, loán/ dole ciertas obras que hizo» en la que se elogia a «cierto» cortesano que ha publicado «cierto» libro de cartas donde el remitente asegura «recoger algunas flores del estudio para texeros una guirnalda que denote lo que merece vuestra fa/ma» (Texeda, 1553, 50: ff. XXXI v-XXXII v; la cursiva es nuestra), bien podrían proceder de intercambios epistolares reales. Paralelamente parece bastante plausible considerar ficticios otros modelos como la «Carta graciosa y de veras en metro prosa, de un cavallero moço/ a un señor viejo» que comienza:

Muy excelente señor: ya ningún apoyo pre/sta quando la casa se acuesta y no hay se/ñal de calor. No deys tantas aldava/das que, mi palabra os empeño, do están/ las puertas cerradas nunca responde/ su dueño. Pues no me paresce bien,/ por amor o por antojo, untaros sola la/ sien, teniendo quebrado el ojo. (Texeda, 1547, 286: f. S v)

5 Le precede la miscelánea Obra en gramática, rhetórica y poesía del bachiller Fernando de la Pradilla (1502?), pero esta no parece en rigor un formulario de cartas, sino un repertorio bilingüe orientado a la instrucción escolar del latín.

6 Martín Baños (2005a: 452-457) señala que la tradición epistolar vernácula se desarrolla a partir de 1476 en Alemania con la aparición de retóricas como Formulare et deustch Rhetorica y en Italia con unos anónimos Soprascritti ed introscritti di lettere (1480) y un Formulario di epistole volgare missive e responsive et altri fiori de ornati parlamenti (1485), atribuido en unas ediciones a Cristoforo Landino y en otras a Bartolomeo Miniatore. En Francia la primacía corresponde a Le grant et vray art de pleine rhétorique (1521) de Pierre Fabri, seguido del Prothocolle des secretaires (c. 1534) del enigmático Pierre Durand. No obstante, todos ellos continúan en gran medida la línea establecida por las artes dictaminis en la tradición latina. Castillo Gómez (2002: 88) solo señala un precedente del manual español, el atribuido a Bartolomeo Miniatore, publicado por primera vez en Venecia en 1475.

7 Incluyo aquí las cartas en las que los dos o, al menos, uno de los corresponsales pertenece al sexo femenino y también aquellas cuyo asunto fundamental se deriva o está directamente relacionado con la mujer.

8 En la edición de 1547 , representan un $32,5 \%$; en la de 1549 , un $31,8 \%$ y en la de 1553 , un $41,2 \%$. Por su parte, en el Segundo Libro (1552) constituyen un significativo 44,9\% (Navarro, en prensa). La diferencia con respecto a los formularios coetáneos es evidente: las cartas femeninas del Estilo de escrivir cartas mensageras de Juan de Yciar (Zaragoza, 1552), por ejemplo, suponen tan sólo el 12,2\% y, además, actúan en un ámbito claramente delimitado, pues todas ellas son respuestas a previas cartas masculinas y cartas de cumplimiento. 
$\mathrm{O}$ la «De un cavallero moço preso en poder de un/ rey estraño a su muger estando sentenciado a de/gollar. Y despidiéndose della con estos ren/glones desde el cadahalso», que inverosímilmente concluye «No/ quiero dilatarme más por no detener al verdugo» (Texeda, 1553, 9: ff. XIIII r-v)

Muy a menudo la diferencia entre la carta aparentemente real y la imaginada parece depender sobre todo de pruebas y testimonios externos, lo que en la práctica elimina la frontera entre unas y otras. Desde el preciso instante en que una carta real se integra en un repertorio, esta deja de ser «totalmente real», porque el compilador-autor de la colección deberá adaptarla, sometiéndola necesariamente a algún tipo de retoque: bien corrección, bien impersonalización (supresión de nombres, lugares, fechas...), o bien pulimento de estilo. En definitiva, deberá someterla a cierto proceso de elaboración técnica, digamos «artificial». A su vez, las cartas inventadas habrán de tener, ante todo, la pretensión de parecer reales. No olvidemos que el objetivo de estas obras es que el lector aprenda a escribir cartas oficiales y privadas, imitando los buenos ejemplos del dictamen. La finalidad pedagógica se vería seriamente comprometida -cuando no malograda por completo- si el aprendiz sospechara que los modelos epistolares que usa son ficticios y se basan en una mentira con poco o ningún anclaje en la realidad. Por tanto, las cartas de tratados y manuales han de cumplir inexcusablemente el requisito de la «apariencia de realidad» (Violi, 1999: 190), lo que Guillén (1998: 185) definió como «ilusión de no ficcionalidad». Así pues, al trabajar con este tipo de manuales didácticos contamos con cartas que no son propiamente «auténticas», pero tampoco propiamente «ficticias» ni «literarias»: son cartas «fingidas», esto es, cartas que aspiran a pasar en algún grado por auténticas (Guillén, 1998: 192-193). Por consiguiente, la inventio, la dispositio y la elocutio de estas cartas reflejarán con bastante fidelidad las empleadas en su práctica cotidiana por los hombres y las mujeres que fingidamente las escriben.

Es preciso advertir asimismo que la carta es el escrito que mejor revela el carácter de quien lo escribe. No en vano se ha definido desde la Antigüedad por su capacidad de autorrepresentación como espejo o retrato del alma del remitente (Demetrio, 1979: 97), rasgo al que también alude Gaspar de Texeda en el «Aviso de un notable vicio en escrevir» que abre su Segundo Libro:

Dizen que en una carta, más que en otra ninguna de/mostración, vemos el retrato de lo que alcança el que/ la escrive. Y por eso parece que este officio de es/crivirlas no basta saberse razonablemente,/ pues a de ser verdadero testimonio del origen de donde sale. (Texeda, 1552: f. iii r)

Ciertamente debemos plantearnos cómo se articula esta característica en las cartas fingidas del Libro de cartas mensageras. Por supuesto, es Texeda quien escribe a través de las damas, los cortesanos, las monjas, los reyes, las viudas, los prelados, las mozas y los hidalgos que pululan por su muestrario. Pero, en la composición de sus cartas, Gaspar de Texeda tiene bien presente que un buen secretario -y por ende cualquiera que ordene una carta en nombre de otro- ha de adoptar la imagen y el carácter del suplantado, asumiendo su voz y sus intereses, aun cuando este sea manifiestamente inhábil en el arte de componer cartas. Así lo advierte nuestro epistológrafo en sus «Avisos» preliminares:

A de preciarse de conservar el auctoridad de su a/mo [...]; co/mo lo podrá hazer el que supiere seguirse por la condi/ción, prudencia y providencia del señor, contraha/ziéndole su 
manera de hablar, proceder y negociar/ para que las cartas no parezcan de palabras agenas. (Texeda, 1553: f. A viii r; )

Pues el escrevir atinadamente o con destien/to, es cosa que ha de parescer firmada del nombre del quien lo embia, (Texeda, 1549: f. A iii r; el subrayado es nuestro)

De esta manera los modelos epistolares del formulario que vamos a ver ofrecen en rigor la perspectiva masculina del autor, su mirada y su retórica de hombre. Pero, si aplica en su composición los principios que él mismo establece -y es de esperar que sea así-, entre las líneas de sus cartas se deslizarán inevitablemente el carácter, la voz y el estilo epistolar que, según el autor, exhibe toda clase de hombres y mujeres. Ciertamente este «transformismo» autorial no está exento de ficcionalidad, pero ni siquiera las cartas llamadas reales lo están, porque el «yo» que escribe, no lo olvidemos, manipula siempre en cierta medida su propia imagen, ofreciéndonos el retrato preferido de sí mismo, el deseable o el deseado, esto es, una identidad creada a voluntad y no siempre conscientemente ${ }^{9}$. En este sentido, las cartas texedianas no difieren significativamente de la correspondencia real. Es verdad que no reflejan las estrategias y argumentos retóricos empleados por los remitentes en sus cartas cotidianas, pero sí aquellos que Texeda -perspicaz epistológrafo por cuyas manos debía de pasar diariamente un substancial número de cartas masculinas y femeninas- consideraba más característicos de los corresponsales de uno y otro sexo.

Finalmente, conviene plantear una última cuestión previa: hombres y mujeres ¿escriben de modo diferente sus cartas? Así parece si atendemos a las recomendaciones que facilitan los propios secretarios en sus manuales. Unas veces estas observaciones sustentan en realidad criterios jerárquicos de rango ${ }^{10}$, como ésta de Texeda: «A señores estrangeros y a señoras/ siempre se les ha de escrevir con acre/scentada cortesía.» (Texeda, 1547: f. v r); o bien combinan orden social y parentesco, como hace Antonio de Torquemada en el apartado destinado a la carta consolatoria de su Manual de escribientes (1552):

porque, según las calidades de las personas, así se han de escreuir diferentemente, [...], porque de vna manera se ha de escreuir al que se le muere la muger, que al que se le muere algún hijo, y diferentes han de ser las cartas a las mugeres a quien se les muere el marido, que a quien se le murió el hermano; (Torquemada, 1970: 229)

Otras observaciones, apuntan diferencias más profundas en la realización epistolar que atañen a la elocución, al buen gusto y al decoro. Así lo revelan, por ejemplo, el «aviso» de Texeda respecto a los títulos y cortesías y la anécdota que cuenta Torquemada sobre dos cartas iguales:

Las mugeres tienen otra ley en el/ escrevir, que siempre cercenan los títulos y corte/sías.// No ponen señoría al que no es muy gran/de.// Escriven muy magnífico al que es Illustre/ y siempre merced. (Texeda, 1552: f. iii v)

siendo la materia y la sustançia toda vna, auemos de diferençiarlas con razones que no vengan a encontrarse, [...]. Y quando esto no se haze, pareçe torpeza de los secretarios y

9 No en vano Samuel Johnson afirmaba que no hay mayor tentación de falacia y adulteración que el comercio epistolar.

10 Recordemos que en la clasificación de los doce estados principales en que se ordena el mundo, Enrique de Villena (1958: 12) reservaba el último para todo el género femenino. 
falta de razones, y dan ocasión, y avn liçençia, para ser juzgados, y çierto pareçe muy mal, que muy pocos días ha que yo vi en esta casa dos cartas de visitaçión y cunplimjentos de vn grande de este Reyno para el Conde [de Benavente], y para mj señora la Condesa, y en ninguna cosa se diferençiavan si no solamente en el título, que las palabras eran vnas mesmas, (Torquemada, 1970: 225)

\section{LA ASIMETRÍA DE GÉNERO EN LOS TOPOI Y ARGUMENTA DE LAS CARTAS DE RECOMENDACIÓN TEXEDIANAS}

Del amplio abanico tipológico que ofrece la vasta colección epistolar de Texeda, hemos seleccionado el grupo de las cartas de recomendación porque éstas exceden el ámbito de la privacidad al que tradicionalmente se ha circunscrito la práctica escritural femenina y porque su naturaleza, lindante con la correspondencia administrativa y con las cartas de negocios, establece unos estrechos -y estrictos- cauces formales de realización, en los que, en principio, deberían actuar en menor grado los roles sexuales.

Entre las cartas de recomendación, es decir, las que se escriben para favorecer a amigos o deudos, o bien algún negocio de estos, son escasas las cartas femeninas. Llama poderosamente la atención la parquedad de modelos femeninos que presenta el Primero Libro (5 cartas, de las que solo una tiene una remitente mujer; en las otras cuatro, es la mujer la recomendada) en comparación con las 22 que ofrece la Segunda Parte (donde solo una vez se recomienda a la mujer, amiga de la remitente, en tanto que en todos los demás casos la mujer ejerce de remitente, mayoritariamente, o de destinataria). En todos los casos, como es de esperar, las cartas femeninas están numéricamente peor representadas que las recomendaciones masculinas (17 en la ed. de 1553 y 27 en la ed. de 1552). Trabajamos, por tanto, con el total de las 71 cartas de recomendación diseminadas en las ediciones de 1549, 1552 y 1553.

La carta de recomendación es un subtipo epistolar extremadamente delicado de componer pues, como señala Torquemada en su Manual de escribientes (1552), la fuerza y la eficacia de la encomienda dependen en gran parte de la habilidad y vehemencia estilística de quien escribe:

no son estas cartas donde menos discreçión y consideraçión han de tener los secretarios para subirlas o vaxarlas de punto en algunos encareçimientos, porque en las mesmas cartas se conoçe y entiende la voluntad de aquel que las da, [...], porque las cartas que se dan a personas que ynportunan por ellas, de quien no se tiene otra obligaçión ninguna, van con vnas palabras llanas y hordinarias, sin encareçimiento, y las que son para personas por quien el señor desea hazer, pondera el negoçio y encaréçelo, estimando lo en mucho y replicándolo con palabras fuera del estilo hordinario, y haziéndolo negoçio propio (Torquemada, 1970: 236)

La estructuración ortodoxa del tipo según los manuales de la época es simple y supone una considerable reducción con respecto a las cinco partes del formato aprobado de la carta medieval. Siguiendo las indicaciones del Manual de Torquemada, la carta ha de comenzar contando el caso, ha de continuar pidiendo lo que se pretende y ha de concluir encareciendo el favor que constituye la causa. La primera diferencia significativa 
que encontramos entre las cartas de recomendación que Texeda atribuye a los hombres y las que finge salidas de la pluma femenina atañe a la presencia o ausencia del exordio, parte imprescindible, según la preceptiva epistolar clásica, para captar la atención y la benevolencia del destinatario. La inmensa mayoría de los remitentes varones de Texeda introducen sus cartas directamente con la exposición del caso a recomendar, observando así las indicaciones que en este sentido ofrecen los tratados para secretarios (Torquemada, 1970: 237):

Fulano trae un pleyto ante vuestra merced sobre tal/ cosa, en que en su tierra ha recebido agravio/... (Texeda, 1549, 82, «De recomendación de más a juez sobre des/pacho de negocio de particular»: f. E viii r)

El señor fulano trata un pleyto en esa corte/ sobre cierto fuero de su patria, y será el/ mayor desafuero del mundo no mandalle/ Vuestra Señoría despachar brevemente y muy bien (Texeda 1552, 306, «De un cavallero a un señor que tiene cargo de/ la govarnación de un reyno, en recomendación/ de un negocio que procura un amigo suyo»: f. P vii v)

El señor fulano tiene cierto pleyto en esa audien/cia sobre... (Texeda, 1553, 64, «En recomendación de un pleyto»: f. XXXVIII r)

En casos aislados la carta esboza una captatio benevolentiae y se abre con un elogio al destinatario por sobrepujamiento - «Por ser vuestra señoría tenido por la persona del mun / do que de mejor gana favorece la virtud, / y a los que se casan con ella» (Texeda, 1553, 72, «A un perlado en recomendación de una per / sona sabia, muy virtuosa y de buena doctrina.» f. XL v)-, o bien comienza de forma excepcional con algún tipo de cumplimiento, como el referido al contacto epistolar sostenido regularmente entre los comunicantes:

Con el correo passado respondí a las de vuestra / merced y dixe todo lo que hasta entonces me o- / curría. Después acá no ay cosa nueva que de /zir sino que el señor fulano es llegado a esta corte / con salud y mucho contentamiento, de que todos le te / nemos, por lo que merece su persona, áse ofrecido pa / ra todo lo que tocare a vuestra merced y a sus cosas con tan bue / na voluntad, (Texeda, 1553, 79, «De un amigo a otro, avisándole de los / ofrecimientos de un señor, y encoménda / le sus negocios»: f. XLIII r)

Por el contrario cuando la remitente es mujer lo común es que la carta presente algún tipo de introducción exordial, en cuya formulación sorprende la variedad y el conocimiento retórico clásico que exhiben las peticionarias ${ }^{11}$. Si la carta femenina principia con el preámbulo socialmente reconocido del cumplimiento, éste se entrelaza con algún otro topos propio de la captatio benevolentiae, como el de la humilitas, desarrollando, por ejemplo, la supuesta inexperiencia epistolar de la señora remitente:

Si todas las horas del mundo hiziese esto, sabría qué hazer para cumplir con mi desseo para solo saber de la salud de Vuestra Señoría y de mi señora la condesa, Vuestra Señoría me saque deste cuydado con solos dos renglones, porque rescebiré señalada merced en ello. (Texeda, 1552, 127, «Carta de recomendación en que una señora pide a un grande que haga proveer a un amigo suyo»: $\mathrm{f}$. $\mathrm{H}$ iii r)

11 No obstante, hay una carta que expone directamente el caso a favorecer (Texeda 1552, 270, «De una señora favoreciendo a un amigo suyo muy de veras»: f. O iiii v) 
Otras veces la humilitas convive con la indignatio y con la commiseratio en cartas tan sumamente emotivas y conmovedoras como «la que una gran señora biuda» escribe a un presidente en favor de «una casada que le levan/taron falso testimonio»:

Si por escrevir sobre cosa de tal calidad pares/ciere que la auctoridad es menor que la ma/ teria, atribuya Vuestra Señoría la culpa a la fortuna/ que ha hecho que los parientes de fulana/ la desamparen y aborresca[n] sin propósito. La necessi/dad que la pobre señora tiene de quien la socorra, haze/ que las tinieblas en que estoy parezcan más claras de lo que debrían. (Texeda, 1549, 257, «Carta de favor de una gran señora biuda...»: ff. Q ii r- Q ii v)

La humilitas también puede dilatarse hiperbólica y desmesuradamente, invadiendo prácticamente todo el escrito, mediante argumentos de jerarquía y de amplificación por comparación (Perelman, 2000: 516-535 y 375-382), como sucede en la carta que una dama dirige a un presidente para recomendar a una amiga por quien previamente ya han intercedido otras personas de valor:

Donde an llegado tantas cartas y de tanto valor y fuerça en recomendación de los negocios de la señora fulana, no sé para qué quieren la mía que ni tiene vigor ni poder, para de sí misma hazer efeto, si no fuesse que como los ríos famosos, no desdeñan a los pequeños que corren en su compañía hasta la mar, assí pienso yo que el arroyo de poco estruendo que hago, aunque de sí mismo no puede ser de provecho, parece que corriendo en compañía de las bravas hondas del río caudaloso de la duquesa mi señora puedo tener por cierto que llegare a noticia de Vuestra Señoría (Texeda 1552, 251, «Graciosa de una dama...»: ff. N v v- N vi r)

Desde la Antigüedad los preceptistas recomendaban evitar en la correspondencia epistolar cualquier asunto desagradable o embarazoso para el destinatario (Symmaque, 1972, II-49: 187), y una petición de favor para terceros puede ser a menudo enojosa e incluso fuera de razón. Así que las mujeres texedianas dedican con frecuencia las primeras líneas de sus escritos a justificar pudorosamente su atrevimiento, bien subrayando su mero papel de mediadoras frente a la autoridad -realzada por contraste- del destinatario del escrito $-\ll$ Como todos me tienen por privada y servidora de Vuestra Señoría y tienen necessidad de favor acuden a mí para que lo alcance». (Texeda, 1552, 127, «Carta de recomendación en que una señora pide a un grande que haga proveer a un amigo suyo»: f. H iii r)-, bien vinculando la escritura al propio carácter de la remitente, quien se vería gravemente menoscabada si desatendiera, por mera cortesía epistolar, la intrínseca virtud de la piedad o el inexcusable deber de gratitud $^{12}$ :

Yo querría mucho socorrer a los que se me encomiendan sin dar pesadumbre a nadie, como si dixesse que desseo hazer bien sin terceros. Vuestra merced sabe el trabajo de fulano (Texeda, 1552, 268, «De una señora a un juez, en favor de un acusado contra derecho»: ff. O iii v- O iiii r)

Aunque propongo mill vezes de no dar pesadumbre con estas cosas, parece que algunas no pueden yr por esta ley, so pena de usar de mucha ingratitud. Y ansi lo sería yo agora, si no favoreciesse al portador desta (Texeda, 1552, 245, «De una señora a un presidente, en recomendación de cierto negocio de un criado de su padre, pídelo con instancia»: ff. $\mathrm{N}$ iii $\mathrm{v}-\mathrm{N}$ iiii r)

12 Obsérvese que además los motivos de estas cartas eximen de responsabilidad a las peticionarias, quienes son constreñidas por las circunstancias a realizar las respectivas demandas. 
Otro medio preceptuado como eficaz para recabar la atención y la adhesión del destinatario en el preámbulo epistolar es el uso de sentencias o máximas (Lausberg, 1990, I: 247) que, sujetas a la presunción de acuerdo general, solo pueden ser rehusadas excepcionalmente. Aunque su uso no es ajeno a la práctica masculina tal y como la concibe Texeda ${ }^{13}$, es éste un recurso más frecuente en las cartas fingidas de las mujeres: «Y como dize un proverbio que no ay cosa que engendre mayor plazer que hazer plazer, quiérolo hazer a un criado mío» (Texeda, 1552, 253, «De una dama en que pide una merced a un grande para un criado suyo»: f. $\mathrm{N}$ vi v)

La raigambre clásica de la epistolografía femenina se vislumbra igualmente en una cartita peculiar, la recomendación «donosa» de una mujer. La configuración elocutiva elegida para desarrollar lo que se descubrirá como motivo de encarecimiento del recomendado, es ciertamente en este modelo muy arriesgada, hasta el punto de que la primera impresión que recibe el receptor puede resultar inconveniente. Veamos primero el exordio femenino al que nos referimos:

El caso muy de ver que no tengo de escrevir a / vuesa merced con las palabras de los antiguos quan / do encomendavan los negocios, porque lo / pedían con dos condiciones: si la cosa fue- / sse justa y onesta. Y aun lo tenían por ley que nadie pu / diesse recomendar de otra manera, la qual a mí no me / conviene, porque si lo que pido es justo, y aun justíssi / mo, de suyo se le deve ser favorecido y mirado, y en esto / no sé para qué me valen mis recomendaciones ni las / de nadie teniendo la causa de por sí viva verdad y tan / verdadera justicia como la que tiene fulano. (Texeda, 1553, 236, «Donosa manera de recomendación de una muger»: $\mathrm{f}$. XCV v; la cursiva es nuestra)

Verdaderamente el resultado global de la introducción epistolar no es muy afortunado, pero es interesante destacar que el motivo usado por la mujer denota un buen conocimiento de la tópica epistolar característica en la recomendación, así como un gusto por la variatio y por la auctoritas de lo precedente, independientemente de que esta sea transgredida con el uso del argumento a contrario, esto es, la no aplicación de lo que se afirma (Perelman, 2000: 374). Y es este un conocimiento del que se desvinculan los modelos recomendatorios masculinos. La formulación exordial de esta cartita, basada en la combinación de litotes, antífrasis y expolitio conceptual, provoca una premeditada ambigüedad en la exposición del motivo. Evidentemente, de la lectura de las primeras líneas, parece deducirse la injusticia y la deshonestidad de la causa del recomendado, interpretación que será corregida explícitamente de inmediato -«porque si lo que pido es justo y aun justíssimo»-, contraviniendo el devenir argumentativo lógico y provocando la sorpresa del lector. Desde luego, el recurso es ingenioso, pero excesivamente rebuscado y retóricamente cuestionable porque suscita innecesarias sospechas en torno al favorecido que no son diestramente refutadas después. Es más, la remitente olvida en la supplicatio la clave argumental usada y solicita al destinatario no que dirima en justicia, sino que directamente desoiga a la parte contraria: «Suplico/ a vuestra merced le favorezca cerrando los oydos y los ojos a/ la desenfrenada malicia de sus adversarios» (Texeda 1553, 236, «Donosa manera de recomendación de una muger»: f. XCV v)

13 Encontramos un caso en la ed. de 1549, la carta «De recomendación de un cavallero a un ami/go suyo, intercediendo por otro» (188: f. L ii r) 
El uso es opuesto al que presenta buena parte de los modelos masculinos de recomendación, donde la argumentación que avala la demanda se limita prácticamente a señalar su obligatoriedad según derecho:

suplico a Vuestra Señoría me la haga de tenello por bien, que para mayor satisfación de Vuestra Señoría y del derecho que el dicho mi criado tiene a ella, él mostrará su justicia a dos letrados de vuestra señoría reverendíssima, y teniéndola entonces podré yo recebir esta merced. (Texeda, 1552, 256, «De un perlado a otro, en recomendación de un negocio de un privado suyo»: ff. $\mathrm{N}$ vii $\mathrm{r}-\mathrm{v}$ )

Fulano me ha escripto la buena voluntad / que vuestra merced tiene para mirar la justicia que / pido, sabiendo que importa mucho al de / recho y preminencia de mi dignidad y / que la estimo como es razón. Afectuo- /samente le pido por merced tenga la causa por muy / encomendada como de su gran rectitud se espera (Texeda, 1553, 37, «De un arçobispo a un audictor en recomen- / dación de una causa tocante a su dignidad.»: f. XXVII v)

Suplico a vuestra merced mande que / se vea su derecho y se despache con breve- / dad, haziéndole la buena obra que median / te justicia oviere lugar (Texeda, 1553, 64, «En recomendación de un pleyto»: f. XXXVIII r)

Esta práctica aparece asimismo, aunque de forma esporádica, en la configuración de algunas petitiones femeninas. Sin embargo, rara vez se atienen a la exposición simple y escueta ejercitada por los hombres. Ocurre, no obstante, ocasionalmente, como en la recomendación del criado del padre de la remitente: «suplico a Vuestra Señoría me haga merced de mandar que se mire su justicia» (Texeda, 1552, 245, «De una señora a un presidente, en recomendación de cierto negocio de un criado de su padre, pídelo con instancia»: ff. N iii v- N iiii r). Por contra, la petición legítima suele someterse en las cartas femeninas a algún tipo de elaboración retórica que realce su contenido. Así, la señora que recomienda a su amigo, el «secretario de [su tío el] duque del Ynfantadgo», atenúa su demanda mediante la litotes y la prolepsis, desarticulando con eficacia una posible objeción de incompatibilidad (Perelman, 2000: 271-272 y 306-307) entre justicia y amistad por parte del juez destinatario:

pedir a vuestra merced le favorezca no bolviéndose el filo derecho de la justicia, porque lo pido con esta condición: que aunque los juezes sean obligados a ello, no se rompen las leyes ni la justicia por mirar que no se pierda la de los amigos. (Texeda, 1552, 248, «De una señora a un juez, en recomendación de una causa de un amigo suyo»: ff. N iiii v-N v r)

Otros motivos indispensables en este tipo de cartas son el encarecimiento de la causa y el elogio de la figura del recomendado. En general ni uno ni otro faltan en los modelos texedianos masculinos. Los remitentes suelen manifestarse sobrios en la ponderación o encarecimiento de lo solicitado, limitándose a presentarlo como propio:

Y qualquiera cosa que / por su persona y procuradores se hiziere, lo estimaré en / más que si a mí se me hiziesse la merced. (Texeda, 1549, 76, «De más a menos, en negocio»: f. E vi r)

terné yo en tanto que por mi / respecto se le haga alguna manera de gratificación, / como si por mi propia persona se hiziesse. (Texeda, 1553, 84, «A un juez en recomendación de cierto negocio»: $\mathrm{f}$. XLIIII v) 
Sin embargo, se detienen largamente en la lisonja del recomendado. Ésta es en realidad la sección más cuidada en la mayoría de los ejemplos masculinos recomendatorios del Libro. La mayor parte de los alardes retóricos que apreciamos en estas cartas se concentran precisamente aquí. Para ello los hombres no dudan en utilizar artificios elocutivos como la enumeratio, la metáfora, la hipérbole y el sobrepujamiento:

me pareció da / lle noticia del portador de la presente que es / fulano a quien Dios Nuestro Señor a dotado de singu / lar erudición y doctrina para todo lo que le quisieren. / Vuestra Señoría goze de su claro juyzio, que los que por acá le co / nocen y alcançan el fundamento de lo que sabe, publi / camente nos dizen que es la llave de los secretos que ce / rraron los patriarchas y prophetas en lo profundo de / la escriptura sagrada. (Texeda, 1553, 72, «A un perlado en recomendación de una per / sona sabia, muy virtuosa y de buena doctrina.»: f. XL v)

Demás de esto quiero vendérosle por hom / bre tan bien agradecido que conocerá lo que se hizie / re por él, y sabrá perder la vida, antes que la joya del / esfuerço con que se gana la gloria de la fama. Con estas / condiciones puede vuestra merced fiallo de su persona que mere I cerá toda la honrra que se le hiziere (Texeda, 1553, 108, «De un cortesano a un amigo suyo en recomen/dación de uno que va desafiado»: ff. LII v- LIII r)

No he respondido antes a la de Vuestra Señoría / por acertar en el mensagero, y por aca / bar de saber la relación y calidades de fu / lano. Ella es tan buena que ponemos dub / da si en el reyno se halle otro ingenio co / mo el suyo para lo que Vuestra Señoría le quiere, assí de natural, / sabio, diligente y d'entendimiento como de maravillo / so estilo, inteligencia y experiencia de negocios, y un / artificio en lo de las cartas que parece sobrenatural / con ser muy buen hidalgo que vale más que todo. Vuestra / señoría le procure y, si le oviere, le conserve con favores y mer / cedes para servirse de la mejor pieça que tiene señor / en España, (Texeda, 1553, 303, «De un cortesano a un grande, avisándole de las / abilidades que tiene uno que desea para secretario»: f. CXXI r; el subrayado es nuestro)

En cambio, las epistológrafas desarrollan escasamente estas dos partes de la carta de recomendación. Integran algún tipo de ponderación de la causa, variando la formulación masculina y definiendo a menudo la petición como «merced», de modo que esta revierta directamente sobre la peticionaria, quien llega incluso, en la carta 275, a desear suplantar físicamente al beneficiado:

y será para/ mí una merced muy señalada (Texeda, 1552, 245, «De una señora a un presidente, en recomenda/ción de cierto negocio de un criado de su padre,/ pídelo con instancia»: f. $\mathrm{N}$ iiii r)

que recebiré yo tanta merced en ello co/mo si la causa fuesse mía y me fuesse en ello el estado. (Texeda, 1552, 248, «De una señora a un juez, en recomendación de/ una causa de un amigo suyo»: f. $\mathrm{N}$ v r)

y no lo quiero encarecer más de que si vuestra merced me man/dasse poner donde él está lo sufriría por velle libre. (Texeda 1552, 275, «De una dama a un alcalde, en recomendación/ de un cavallero encarecidamente»: $\mathrm{f}$. O vi r)

A su vez las mujeres de Texeda que escriben este tipo epistolar se muestran tremendamente parcas en el elogio de sus recomendados -que desaparece por completo en algunos modelos, como el 243 y el 251 (ed. 1552)-, en especial si las comparamos con sus colegas varones:

si no favoreciesse al portador desta, a/ssí por aver sido criado de mi padre como porque lo/ merece su mucha virtud (Texeda 1552, 245, «De una señora a un presidente, en recomenda/ción de cierto negocio de un criado de su padre;/ pídelo con instancia»: f. N iiii r) 
que él es hombre de tan/ buena confiança y diligencia que será bueno pa/ra el officio y aun para servir a Vuestra Señoría, (Texeda 1552, 253, «De una dama en que pide una merced a un gran/de para un criado suyo»: $\mathrm{f} . \mathrm{N}$ vi v)

Ya sabe vuestra merced que fulano fue secretario del duque del Ynfantadgo, mi señor y mi tío, y que fue tan querido y privado como lo merece su gran virtud. (Texeda 1552, 248, «De una señora a un juez, en recomendación de una causa de un amigo suyo»: f. $\mathrm{N}$ iiii v)

La loa es fría e insubstancial, incluso cuando se trata del propio marido y lo que se pretende es mantenerlo en el sabroso cargo de gobernador:

el señor Almirante/ me hizo a intercessión de Vuestra Señoría de la governación/ de sus estados, para don Gaspar, mi señor. Él reside/ en el cargo y haze lo que deve, de manera que el se/ñor se tiene por muy servido y los súbditos están/ bien tratados y contentos (Texeda, 1552,278 , «De una muger de un cavallero, en que pide a/ una señora que, pues por su intercessión le die/ron un cargo a su marido, que haga que se le den/ para adelante»: f. O vii r)

Tanta moderación expresiva llama fuertemente la atención porque, en una carta de este tipo, el encarecimiento y elogio de la causa no son en absoluto motivos secundarios de carácter ornamental, sino que se convierten en el núcleo vital de la argumentación suasoria que ha de fundamentar la defensa del caso. Recordemos la lección que en este sentido daba Torquemada a los escribientes:

porque las cartas que se dan a personas que ynportunan por ellas, de quien no se tiene otra obligaçión ninguna, van con vnas palabras llanas y hordinarias, sin encareçimiento, y las que son para personas por quien el señor desea hazer, pondera el negoçio y encaréçelo, estimando lo en mucho y replicándolo con palabras fuera del estilo hordinario, y haziéndolo negoçio propio (Torquemada, 1970: 236)

Por consiguiente, cabría esperar que las cartas femeninas de recomendación representadas en el formulario de Texeda fuesen más tibias e ineficaces que las masculinas. Sin embargo, no parece así. Lo que ocurre es que, en las cartas de las mujeres -a quienes tanto les gusta ser loadas-, el centro de interés epistolar se desplaza del recomendado, objeto de la comunicación, a la propia comunicante. Así, la mujer que escribe la carta se constituye ella misma en argumento esencial de la defensa, mediante el enaltecimiento subrepticio ab persona (Lausberg, 1990, I: 250-252). De este modo, el destinatario queda obligado, claro está, por la rectitud de la causa y por el merecimiento del protegido, pero sobre todo, por encima de todo, por la autoridad y la calidad de la remitente peticionaria, cuya reputación caerá en demérito si el recomendado no obtiene el beneficio prometido. Así lo formulan las mujeres:

a la qual suplico tenga por/ bien de mandar ver la causa de la señora fulana con tan/ta benignidad que pueda yo alegrarme con ella/ de averle hecho este servicio (Texeda 1552, 251, «Graciosa de una ama, a un presidente, en re/comendaciónde una causa que toca a una muy a/ miga suya por quien an intercedido otras per/sonas de mucha calidad»: ff. $\mathrm{N} \mathrm{v} \mathrm{v-N} \mathrm{vi} \mathrm{r)}$

Y que será para mí una mer/ced muy grande, saber que vuestra merced le favorece en ello/ y que le aprovecha mi intercessión, assí por la confi/ança que tiene en ella como porque 
yo soy ambi/ciosa de que le valga mi respecto (Texeda, 1552, 277, «De una señora a un juez, en recomenda/ción de un hidalgo»: f. O vii r; somos responsables del subrayado)

vuestra merced hará lo/ que deve haziéndome a mí toda la merced que le pi/do. (Texeda, 1553, 236, «Donosa manera de recomenda/ción de una muger»: f. XCV v)

Quizá sea este un recurso ególatra, pero es absolutamente rentable desde la perspectiva retórica. El encomio discreto y prudentemente sostenido de las remitentes ejemplificadas en estas cartas incrementa los affectus (simpatía, amor, compasión, benevolencia) del destinatario con mucha más facilidad que el mejor elogio posible de la persona encomendada. A todas luces resulta más convincente para cualquier receptor la exaltación demostrativa de la virtud de alguien concreto, conocido, próximo, con quien existe alguna vinculación previa -la remitente- que la loa del recomendado, alguien extraño, indiferente, desconocido o lejano; una loa susceptible de no ser justamente creída ni valorada.

De manera excepcional el elogio de la persona a quien se quiere ayudar es sustituido por la commiseratio. Texeda propone dos ejemplos de este uso, uno masculino y otro femenino. Sin embargo, el tono y la formulación que exhibe la commiseratio en estos modelos son ligeramente distintos:

y por ser biuda y po/bre deseo ayudalla en algo para que/ su causa sea bien expedida. (Texeda, 1553, 88, «De un perlado en recomendación/ de cierto negocio de una biuda»: f. XLV v)

Vuestra merced lo haga teniendo a memoria que la pu/ra simplicidad deste pobre hijodalgo se vee opre/sa de la malicia. (Texeda, 1552, 268, «De una señora a un juez, en favor de un/ acusado contra derecho»: f. O iiii r)

En consonancia con su dignidad, el prelado actúa por caridad, presentando el asunto de la viuda como obra piadosa y de misericordia y, por tanto, de obligado cumplimiento. En cambio, bajo la apreciación de la señora subyace en realidad la convicción de una superioridad jerárquica e intelectual que se resuelve en condescendiente indulgencia, a la vez que sugiere un cierto distanciamiento y menosprecio - «la pura simplicidad deste pobre hijodalgo»- hacia la figura del criado. Es evidente que ambas conmiseraciones revierten también en la configuración del êthos del remitente: magnánimo el eclesiástico; jactanciosa y un punto inclemente, la mujer.

En el encarecimiento del caso y el elogio de la persona recomendada hay, no obstante, un modelo femenino ciertamente singular. Me refiero de nuevo a la carta que una señora viuda escribe en defensa de una casada cuya limpieza de sangre probablemente -o quizá cuya honestidad- ha sido puesta en entredicho por sus parientes y que sufre la ignominia, fomentada al parecer por el marido, e incluso la prisión, si nos atenemos a la versión ofrecida en la edición de 1553. Este es el único ejemplo de recomendación en el que la remitente no se limita a señalar someramente las virtudes del recomendado, mujer también en este caso, sino que, por el contrario, se erige con pasión en fiadora de la inculpada y arremete vehementemente contra el marido, estableciendo un efectivo contraste entre acusador y acusada:

El mayor testimonio de su limpieza,/ es ponerme yo en ampararla de las siniestras infor$\mathrm{ma} / \mathrm{ciones}$ las quales suelen hazer dudar a qualquiera bu/en juyzio. Y ansi he querido escrevir/ 
que yo misma/ he hecho infinitas vezes experiencia de la mucha bon/dad desta señora, en tiempo que ella tenía mejor apare/jo de lo que dizen que agora. Y me paresce cosa extraña/ que la cándida honestidad, bondad y fama de una tal/ muger como ella sea maculada por la malicia de un tal marido como el suyo. (Texeda, 1549, 257, «Carta de favor de una señora biuda/ que intercede por una casada que le levan/taron falso testimonio. Escrívele a un/ presidente»: f. Q ii v)

En esta carta, el encarecimiento de la causa es tal que la remitente compendia y reitera, en una supplicatio geminada, todos los recursos suasorios argumentativamente útiles: el encomio -«la calidad de su persona», «la honrra y buena reputación que su mucha bon/dad meresce»-, la argumentación por los hechos, esto es, la absoluta falta de pruebas contra la mujer, superlativamente significada -«que hasta agora no se ha hallado tras ella la menor cosa del mundo»-, el ruego sagazmente atenuado por la litotes -«vuestra señoría no dé lugar a que la persigan más»-, el uso combinado de máximas o verdades generales y commiseratio, anticipando un fatal desenlace para la injustamente acusada -«pues [vuestra señoría] sa/be que una persona de honrra puesta en la aflición que/ ella está por mejor terná morir que ver su fama en con/dición.»-, la legitimidad que debe regir toda decisión jurídica $-\ll Y$ mande vuestra señoría deliberar esta cosa/ conforme a justicia y razón, restituyendo a esta señora.»-, la mesurada loa al destinatario -«Porque será obra de su gran rectitud»- y finalmente la generalización solidaria de lo que no es sino un caso particular: «Porque será obra [...] de que las mugeres no se tengan por desfavorescidas». Realmente Texeda nos presenta en boca de esta viuda un alegato encantador:

Suplico a vuestra señoría que/ considerada la calidad de su persona, y que hasta agora/ no se ha hallado tras ella la menor cosa del mundo, vue/stra señoría no dé lugar a que la persigan más, pues sa/be que una persona de honrra puesta en la aflición que/ ella está por mejor terná morir que ver su fama en con/dición. Y mande vuestra señoría deliberar esta cosa/ conforme a justicia y razón, restituyendo a esta señora en / algo de la honrra y buena reputación que su mucha bon/dad meresce. Porque será obra de su gran rectitud,/ y de que las mugeres no se tengan por desfavorescidas. (Texeda, 1549, 257, «Carta de favor de una señora biuda/ que intercede por una casada que le levan/taron falso testimonio. Escrívele a un/ presidente»: f. Q ii v)

Siguiendo con el análisis de la dispositio característica de la carta de recomendación, encontramos que esta debe cerrarse con los ofrecimientos del remitente y la rogativa final. Así acontece con frecuencia en los ejemplos de ambos sexos que incorpora el formulario. No obstante, mientras que en algunas cartas de los varones el ofrecimiento mismo se vincula indisolublemente a la fórmula de la conclusio, en las de las mujeres el cumplimiento aparece siempre solo y se torna en alternativa al exiguo topos de la conclusión que ofrecen otros ejemplos:

Y porque su/ merced escribirá otras cosas más largo, en esta yo no lo/ seré, pues sabeys que os tengo de servir sin hazer cum/plimientos. Guarde (Texeda, 1549, 76, «De más a menos en negocio»: f. E vi r)

Y pues no/ está ésta para otro efeto, no alargaré más de que si en/ pago desto vuestra merced quisiere mandar algo de su servicio/ me avise, porque se hará con muy buena voluntad./ Nuestro Señor (Texeda, 1553, 84, «A un juez en recomendación de cierto negocio»: f. XLIIII v) 
y assí quedaré/ encargado dello, para todo lo que vuestra merced mandare. Cuya vida... (Texeda, 1553, 88, «De un perlado en recomendación/ de cierto negocio de una biuda»: ff. XLV v- XLVI r)

y/ en este grado lo conoceré para todo lo que vuestra merced qui/siere mandarme. Cuya vida... (Texeda, 1553, 301, «De una señora biuda a un governador en re/comendación de una criada suya, presa por un/ levantamiento»: $\mathrm{f}$. CXX v)

y por cosa de tanto precio la serviré a vuestra merced en to/do lo que fuere menester, cuya vida... (Texeda, 1552, 268, «De una señora a un juez, en favor de un/ acusado contra derecho»: f. O iiii r)

Y porque la espero/ recebir de Vuestra Señoría no quiero dezir más de que Nuestro Señor... (Texeda, 1552, 245, «De una señora a un presidente, en recomenda/ción de cierto negocio de un criado de su padre/pídelo con instancia»: $\mathrm{f}$. $\mathrm{N}$ iiii r; el topos en cursiva)

En líneas generales estas son las similitudes y las disparidades que presentan las cartas de recomendación normativamente «aceptables» que conforman el Libro de cartas mensageras. Pero no todos los modelos incluidos por Texeda en su repertorio manifiestan una correcta aplicación y un buen uso de los preceptos epistolares. El número de cartas inapropiadas asignadas a la pluma femenina es sensiblemente mayor que el atribuido a la práctica epistolar masculina: tres frente a una.

La inadecuada carta masculina se halla en la edición de 1553. Se trata del ejemplo 228, «De un ciudadano a un señor encomen / dándole un deudo suyo» (f. XCIII r). El modelo es una adaptación jocosa de la carta original 218, en la edición de 1547 (ff. M iiii r-M iiii v), y 242 en la de 1549, cuya rúbrica varía significativamente: «Graciosa y en recomendación de un deudo:/ de un cavallero a un señor» (ff. P i v-P ii r). Evidentemente la omisión del calificativo «graciosa» y la conmutación del remitente - degradado de «cavallero» a «ciudadano»- determinan los restantes cambios que ofrece la última versión de la cartita. Texeda ilustra en esta ocasión un contra-ejemplo de recomendación, parodiando la tosca abbreviatio que un inexperto o inadvertido remitente puede hacer de uno de los motivos exordiales más recurrentes del tipo, el cumplimiento derivado del trato epistolar continuado entre los corresponsales. He aquí los respectivos exordios de una y otra composición:

Ya que vuestra señoría no me haze merced de man/darme escrevir tantas vezes como yo que/rría, por esso no me tengo en menos ni vivo sin/ esperança de estar en su gracia puesto que la di/ferencia de vuestra prosperidad a mi pobreza, me pue/da dar del pie cada hora. Yo sé que por vuestra gran virtud/ no menospreciays a nadie. (Texeda ,1549, 242, «Graciosa y en recomendación de un deudo/ de un cavallero a un señor»: f. P i v)

Aunque vuesa señoría no me haze las mercedes que suele / de escrevirme ni mandar en qué le sirva, no tengo / de dexar de pedillas para lo que se me ofreciere, en con / fiança de lo que vuestra señoría se huelga de hazellas a los que so- / mos suyos, y también a los agenos. (Texeda, 1553, 228, «De un ciudadano a un señor encomen/dándole un deudo suyo»: f. XCIII $r$; la cursiva es nuestra)

Es evidente que la introducción del caballero pretende justificar de antemano la osada descortesía que supone demandar un favor a un superior con quien se mantiene escaso trato. Para ello, el remitente contrapone antitéticamente formulaciones propias de la humilitas y expresiones de deferencia y elogio al destinatario. Naturalmente el artificio 
sublima la posición social del comunicante, pero sobre todo vincula esta irremisiblemente a su condición moral. Este argumento de calidad, hábilmente empleado como captatio por el caballero, predispondrá favorablemente al corresponsal ante la demanda (poner a un deudo suyo, cuyo señor ha fallecido, al servicio de otro buen señor), obligado por la magnanimidad intrínseca a su nobleza.

En el ejemplo de 1553, nos hallamos ante un ciudadano que obviamente no ha captado la esencia del artificio y desconoce dónde reside la fuerza suasoria de la carta del caballero. Lo que se presenta en el modelo 242 de la segunda edición como acto «voluntariamente obligado», derivado únicamente de la virtud, se transforma en la carta 228 en reclamación y en exigencia. En primer lugar, la formulación que atañe a la ausencia de comercio epistolar entre los corresponsales difiere sustancialmente de la empleada por su predecesor: «no me haze las mercedes que suele de escrevirme»/ «no me haze merced de mandarme escrevir tantas vezes como yo querría». Obsérvese que el ciudadano incluye la relativa «que suele» y reduce la forma verbal «mandarme escrevir» a simplemente «escrevirme». Ambas transformaciones elocutivas, aparentemente insignificantes, subvierten en realidad la naturaleza del vínculo que en rigor debe unir a los corresponsales. La perífrasis iterativa «soler escribir» denota habitualidad de trato, circunstancia ratificada por la simplificación verbal, «escrevirme». En efecto, sabido es que un «señor» ordena por su propia mano solo las cartas más privadas, íntimas y familiares, en tanto que confía el resto al quehacer del secretario, esto es, «las manda escribir». Así pues, las primeras palabras de la carta del ciudadano bastan para evidenciar la «gentil discreción de mala criança» contra la que Texeda ya advertía en su «Aviso de un notable vicio en escrevir» (1552: f. iii r). Mientras que el caballero escribe con acatamiento desde una respetuosa y digna subordinación, el ciudadano equivoca su situación, equiparándose a su corresponsal en un plano de igualdad que naturalmente no le corresponde por rango.

La descortesía se extrema con la formulación imperativa del favor, fehacientemente improcedente (Perelman, 2000: 254-257), -«no tengo / de dexar de pedillas para lo que se me ofreciere»-, en contraste con la expresión optativa, propia de la supplicatio, empleada antes por el caballero: «como yo querría», «me pueda dar». La omisión absoluta del topos de la humilitas y de cualquier vestigio preciso y reiterado del motivo laudatorio, indispensables en una buena carta de favor ad maiorem, completan la mordaz introducción del defectuoso modelo masculino con el que Texeda ilustra un mal, al parecer, muy extendido entre los escritores de cartas de la época:

Entre señores, cavalleros y cortesanos se guarda/ muy bien el estilo de escrevir y se usa de la criança que/ es menester en las cortesías y en todo lo demás; pero/ tras esto ay otros muchos que no lo alcançan [...], que pensando dar honrra a sus amos, ge/ la quitan. (Texeda, 1549, «Avisos para cartas»: f. A iii r)

como los que después de gastado mucho/ papel en sus negocios, y quitada la honrra donde pien/san que la hazen, se queda por dezir lo que quieren. (Texeda, 1553, «Avisos para cartas»: f. VIII v)

En contraposición, los desajustes retóricos que presentan las cartas femeninas no proceden tanto de la falta de decoro cuanto de un defecto en el carácter de las propias remitentes. Así, la señora que se dirige «a un grande en recomendación/ de un gentilhombre, encarecidamente», elabora erróneamente el exordio de su carta, porque ma- 
linterpreta las especificaciones de los manuales acerca de la elocución idónea para las recomendaciones no deseadas. El motivo sobre el que la mujer va a sustentar su suasoria pretende subrayar la excepcionalidad del caso que presenta (Perelman, 2000: 135). Para ello, expone en primer lugar una práctica epistolar hecha costumbre, al parecer, en su casa, la de recomendar causas indignas:

Muchas vezes me hazen recomendar personas/ y haziendas que no sé lo que me pido, si no por /intercesión de gentes a quien no se puede negar, y/ desta manera me acaece rogar por personas indig/nas, aunque parece que me salva la buena inten/ción. (Texeda, 1552, 243, «De una señora a un grande, en recomendación/ de un gentilhombre, encarecidamente»: f. M iii r)

Lógicamente la remitente intenta justificar su actuación pasada, usando el topos ad ignorantiam (Perelman, 2000: 370) y el de calidad, aludiendo al valor de su persona y a su virtuosa bondad natural. Sin embargo, es este un recurso retóricamente inconveniente que, lejos de enaltecer la imagen de la remitente, subraya en realidad una flaqueza moral indecorosa. Torquemada avisa expeditamente a sus lectores de lo que conviene hacer en estos casos. En primer lugar, hay que conocer la causa que se va a favorecer, lo que, obviamente, no hace nuestra beneficiaria:

han de tener respeto a la causa por que se dan, y tanbién a la que ay para pedirlas, si es justa o ynjusta, si es buena obra, si es contra razón, si es dificultosa o si es hazedera, porque por vnos términos se ha de pedir lo vno, y por otros lo otro. (Torquemada, 1970: 235)

Y si la causa es indigna, como ella misma señala que suelen ser aquellas que favorece, lo mejor desde luego es no recomendar:

todas las vezes que fuere cosa ynjusta lo que se pidiere, han de huir los secretarios de hazer las cartas y auisar a los señores dello, y todavía quisieren que se hagan, ha de ser con toda tenplança y moderaçión, avnque lo mejor sería que ni el señor lo mandase ni los secretarios les hiziese, cunpliendo aquel refrán que dizen en latín: «quod tibi non vis alteri non facias». (Torquemada, 1970: 235)

Pero si ha de hacerse por necesidad, el remitente debe cuidar en extremo, como ya sabemos, la elocutio epistolar, manejando palabras y expresiones llanas y simples, y prescindiendo de todo énfasis o artificio expresivo, de manera que la misma sencillez de estilo revele abiertamente al destinatario la displicencia del recomendador. Estas advertencias resuenan en el hacer exordial de nuestra epistológrafa, quien en su simpleza equivoca verba y res, identificando estilo llano y sencillo con la manifestación simple y directa de un pensamiento, que por añadidura revierte en su propio desdoro. La impericia de esta mujer en la práctica epistolar -que no el desconocimiento teórico- se constata en todas las partes que constituyen su breve cartita. Mientras que las preceptivas clásicas postulan alguna fórmula, sutil y casi imperceptible, de transitus entre exordio y narratio (Lausberg, 1991, I: 259), la remitente de Texeda opta por explicar detenidamente la utilidad del exordio elegido y su relación con la petición del escrito:

He dicho toda esta arenga para que Vuestra Señoría se/pa que se me ofrece agora a necessidad de pedir lo que/ quiero con más eficacia, porque desseo que se haga. (Texeda, 1552, 243, «De una señora a un grande, en recomendación/ de un gentilhombre, encarecidamente»: ff. M iii r-M iii v) 
Por supuesto, tal precisión es absolutamente innecesaria para un receptor competente en el arte epistolar, como sin duda habrá de serlo el conde o duque al que se dirige la señora texediana. Pero no solo es innecesaria, sino también contraproducente para la suasoria, pues presupone en el destinatario una necedad pareja a la que exhibe la propia remitente. La candidez de esta mujer impregna incluso la conclusio de la carta, recreada sobre el topos de la brevitas y de la humilitas, pero con un evidente sabor a malicioso chismorreo femenino y a indiscreto cruce de dimes y diretes cortesanos: "Y no digo nuevas, porque a Vuestra Señoría no se sufre dezille las cosas públicas, y las secretas no las pueden saber las mugeres.» (Texeda, 1552, 243, «De una señora a un grande, en recomendación/ de un gentilhombre, encarecidamente»: ff. M iii r-v)

La inadecuación al subgénero recomendatorio de la carta «Graciosa de una cortesana a un cavallero, di/ziéndole que no cumple su palabra y que tenga/ por encomendado al portador» es todavía más evidente. Tanto el tono como la ejecución retórica de la cartita serían absolutamente inadecuados e inservibles en una recomendación seria, e impensables en el ámbito administrativo o propiamente negocial. Es evidente que la finalidad perseguida en este modelo no es tanto recabar el favor del caballero para el portador del mensaje, cuanto castigar al destinatario con un ingenioso y divertido reproche por incumplimiento de palabra. En propiedad, este modelo se inscribe en el ritual del galanteo e ilustra un contexto específico de privacidad y complicidad entre los corresponsales. Veamos el texto de la cartita:

Aunque vuestra merced no aya embiado la pieça de/ carmesí ni los vasos ni frutas que nacen/ en essa tierra, ni las otras gentilezas que prometistes,/ no estoy tan airada que no/ me podríades engañar segunda vez. Y porque lo ve/ays claro os embió la ocasión de hazerme merced,/ que será favoreciendo al portador que va a servir/ al señor duque de. Él es persona de tan bue/nas partes que podrá agradar a qualquier prín/cipe y por esto me atrevo a ser su fiadora. $\mathrm{Y}$ en esto quie/ro que vuestra merced me pague la multitud de promesas que ofrecistes. Cuya vida, etc. (Texeda 1552, 280, «Graciosa de una cortesana....»: f. O viii r)

Difícilmente una queja exordial puede originar una satisfactoria captatio benevolentiae, especialmente si el reproche se combina, como en este caso, con la descalificación del destinatario, descrito aquí como embaucador o mentiroso. Por otra parte, el motivo usado por la mujer como introducción recuerda peligrosamente las recriminaciones de las codiciosas heteras de los epistolarios eróticos griegos:

Me gustaría que la casa de una cortesana se pudiera mantener con lágrimas. En ese caso yo viviría espléndidamente, disfrutando del abundante llanto que tú derramas. En cambio, lo que ahora necesito es dinero, vestidos, adornos y servicio. (Alcifrón, 1988, IV: 289)

Pero no creo que lo que me envías sea motivo de orgullo ¡Bonitos regalos! Frutos que apenas valen dos óbolos y un vino cuya juventud ofende. (Eliano, 1999, 8: 32)

En segundo lugar, el caso que conforma la narratio es expuesto por la remitente directamente como servicio compensatorio - «Y porque lo veays claro os embió la ocasión de hazerme merced»-, aunque no falte la correspondiente ponderación del recomendado: «Él es persona de tan buenas partes que podrá...». Finalmente la moderación y la necesaria cortesía de la petitio epistolar ceden su lugar aquí al mandato abiertamente imperativo e imperioso, inadmisible en cualquier demanda de favor: «quiero que vuestra merced me pague la multitud de promesas que ofrecistes...». 
En un clima similar de complicidad y confianza debemos situar la última cartita femenina de la que vamos a ocuparnos: la 238, «Otra muy graciosa manera de recomenda- / ción de una muger a un juez». La destreza retórica enarbolada en la configuración de este ejemplo es notable pero improductiva y, por tanto, inoperante fuera del divertimento cortesano. La misma advertencia que precede al artificio exordial invalida ya la utilidad real del modelo fuera de este entorno: «Para daros que reyr con esta mi nueva ma / nera de favorecer al portador» (Texeda, 1553, 238: f. XCVI r). Esta vez la configuración compositiva del escrito no redunda, como ocurría en el anterior ejemplo, en detrimento de la imagen de la epistológrafa. Como casi todas las otras remitentes, también esta mujer acude en su exordio epistolar a un principio teórico previo, la necesidad de incluir en toda recomendación algún tipo de ponderación encomiástica del recomendado: «avéys de / saber que los que interceden por alguno sue / len aprovecharse de loalle, y encarecer las / muchas obligaciones que le tienen.» (Texeda, 1553, 238, «Otra muy graciosa...»: f. XCVI r). Pero lo hace para infringirlo sistemáticamente, trocando la esperada loa en vejatorio e hiperbólico vituperio del, supuestamente, favorecido portador: «Y / que haré lo contrario porque le quie- / ro mal de muerte y no puedo velle de mis ojos, por / que nunca hizo cosa buena, sino malas y vergonço- / sas para todo su linage.» (Texeda, 1553, 238, «Otra muy graciosa...»: f. XCVI r).

El mérito elocutivo de la cartita radica en el uso argumentativo que la remitente asigna a una contravención tan grave como la señalada. Como hemos ido viendo, de la mera defensa de la calidad e integridad del encomendado, puede inferirse la bondad y nobleza de la causa, y viceversa. Tal razonamiento, basado en la aplicación del argumento cuasi-lógico de simetría (Perelman, 2000: 343-349), es evidentemente falaz y no resistiría una comprobación empírica; pero es discursivamente efectivo por un principio de probabilidad. Nuestra cortesana subvierte sagazmente el consolidado entimema, aplicando simplemente un argumento de superación (Perelman, 2000: 443-445): es posible que por inercia el remitente se instituya en valedor de una causa dudosa, fiado del crédito del protegido; pero es de todo punto impensable que ampare a quien solo suscita su desprecio y animadversión, a no ser que su demanda sea absolutamente cabal e irreprochable. Este hábil ardid suasorio permite a la cortesana transformar un hecho que en principio le era contrario -la execrable condición del amparado-, en un argumento a favor, la excelencia de la causa recomendada. Y es precisamente esto lo que articula nuestra última epistológrafa:

Con todo eso tengo de roga- / ros por él sabiendo que en cierto negocio que tiene an / te vuestro juyzio trata verdad y tiene justicia haréysme / señor merced en que le sea guardada tanto como si la / causa fuesse mía, en pago de que os lo sabré servir y me / recer. Y Nuestro Señor, etc. (Texeda, 1553, 238, «Otra muy graciosa...»: f. XCVI r).

\section{CONClusión}

Así pues, desde la perspectiva de la retórica de género, las mujeres texedianas que ejercitan la práctica epistolar recomendatoria están notablemente impregnadas todavía de los usos y maneras profusamente recomendados por las retóricas clásicas y reformulados por el ars dictaminis medieval. Manejan con fluidez y soltura los motivos y los instrumentos elocutivos más eficaces en la composición epistolar y, muy especialmente, 
los característicos de la captatio exordial. En su mayor parte, las recomendantes gustan de auto-erigirse en núcleo suasorio de sus cartas de favor, postergando procedimientos discursivos más frecuentes -y más cómodos- como el encomio y la argumentación factual. Las cartas femeninas ejemplificadas en el Libro de Texeda manifiestan la elaboración pausada y reflexiva del artificio técnico, con independencia del éxito suasorio conseguido. Es ésta una práctica, al parecer, demodée y poco ejecutada por los hombres texedianos, quienes restringen mayoritariamente su hacer epistolar a las observaciones secretariales más comunes, vigentes en la época. La correspondencia recomendatoria masculina es mayoritariamente utilitaria. Requiere, ante todo, experiencia y crianza, maneras y civilidad, como reitera el autor una y otra vez en su formulario.

Ciertamente las cartas fingidas femeninas exhiben en general mayor novedad, singularidad y variedad elocutivas que las masculinas, formal y conceptualmente más rígidas y estereotipadas. Pero no nos engañemos: si miramos a través de los ojos de Gaspar de Texeda, vemos que estas no son precisamente las cualidades epistolográficas más recomendables. Hombres y mujeres hacen las cartas bien o mal según su juicio, pero solo estas caen en la incorrección, la desmesura o la descortesía epistolar a causa precisamente de la diversidad de los principios retóricos que manejan. Naturalmente los ejemplos graciosos que hemos visto presuponen gran agudeza y donosura por parte de las remitentes texedianas, pero, desgraciadamente, es este un arte que, con demasiada frecuencia, se manifiesta baldío e ineficaz para las mujeres, reducido a mero juego y divertimento cortesano. Y desde luego, a mi modo de ver, si algo no reflejan estas cartitas femeninas, es precisamente esa irreflexión y esa supuesta espontaneidad que tan condescendientemente han venido loando los epistológrafos en la correspondencia de las mujeres y que suscitaron el interrogante que originó este trabajo.

\section{REFERENCIAS BIBLIOGRÁFICAS}

AlCifrón, (1988): Cartas de pescadores, campesinos, parásitos y cortesanas, ed. Elisa Ruiz García, Madrid, Gredos.

Castillo Gómez, Antonio, (2002): «Del tratado a la práctica. La escritura epistolar en los siglos XVI y XVII» en La correspondencia en la Historia. Modelos y prácticas de la escritura epistolar. VI Congreso Internacional de Historia de la Cultura Escrita, I, eds. Carlos Sáez y Antonio Castillo Gómez, Alcalá de Henares, Calambur, 79-107.

Chartier, Roger, (1993): Libros, lecturas y lectores en la Edad Moderna, Madrid, Alianza Editorial.

Demetrio, (1979): Sobre el estilo, ed. José García López, Madrid, Gredos.

DûCHENe, Roger, (1978): «Lecteur de lettres», Revue d»Histoire Littéraire de la France, $\mathrm{n}^{\circ} .78$, 977-993.

Eliano, (1999): Cartas Rústicas, ed. M. Luisa del Barrio Vega, Madrid, Gredos.

Guillén, Claudio, (1998): «La escritura feliz: literatura y epistolaridad» en Múltiples moradas. Ensayo de Literatura Comparada, Barcelona, Tusquets, 177-233.

LAFAYE, Jacques, (1984): «Del secretario al formulario. Decadencia del ideal humanista en España (1550-1630)» en Homenaje a Ana María Barrenechea, ed. Lía Schwartz Lerner e Isaías Lener, Madrid, Castalia, 247-260.

Lausberg, Heinrich, (1990-1991): Manual de Retórica Literaria. Fundamentos de una ciencia de la literatura, Madrid, Gredos, 3 vols. 
LóPez Grigera, Luisa, (1994): La retórica en la España del Siglo de Oro, Salamanca, Universidad de Salamanca.

Marín Pina, M. ${ }^{a}$ Carmen, (1988): «Las cartas de amor caballerescas como modelos epistolares», en La recepción del texto literario (Coloquio Abril 1986), coord. Jean-Pièrre Étienure y Leonardo Romero, Casa de Velázquez, Universidad de Zaragoza, 11-24.

Martín BAÑos, Pedro, (2005a): El arte epistolar en el Renacimiento europeo, 1400-1600, Bilbao, Universidad de Deusto.

- (2005b): «Familiar, retórica, cortesana: disfraces de la carta en los tratados epistolares renacentistas» en Cultura epistolar en la alta Edad Moderna. Usos de la carta y de la correspondencia entre el manuscrito y el impreso, coord. Fernando Bouza, Madrid, Publicaciones Universidad Complutense, 15-30.

Monfasani, John, (1999): «La tradición retórica bizantina y el Renacimiento» en La elocuencia en el Renacimiento, ed. James J. Murphy, Madrid, Visor Libros, 211-225.

Navarro Gala, M. Josefa, (20 I I): «Los modelos discursivos femeninos en la preceptiva epistolar: la «Cosa Nueva» de Gaspar de Texeda», Estudios Humanísticos. Filología 33, 2 I 9-244.

- (en prensa): «La jocosa metamorfosis del canon epistolar: las ediciones del repertorio de Gaspar de Texeda»

Nies, Fritz, (1978): «Un genre femenin?», Revue d»Historire Littéraire de la France, 78, 994-1005.

Perelman, Chaïm y Lucie Olbrechts-Tyteca, (2000): Tratado de la argumentación. La nueva retórica, Madrid, Gredos.

Rice Henderson, Judith, (1999): «Erasmo y el arte epistolar», en La elocuencia en el Renacimiento, ed. James J. Murphy, Madrid, Visor Libros, 391-419.

Symmaque, (1972): Lettres, ed. Jean Pièrre Callu, Paris, Les Belles Lettres, vol. I.

Texeda, Gaspar de, (1547): Cosa nueva. Este es el estilo de escrevir cartas mensageras, sobre diversas materias como se usa. Con los títulos y cortesías. Compuesto por Gaspar de Texeda (Zaragoza: Bartholomé de Nágera). Ejemplar de la Biblioteca de la Hispanic Society of America.

- (1549): Cosa nueva. Estilo de escrevir cartas mensageras Cortesanamente a diversos fines y conceptos con los títulos y cortesías que se usan. Compuesto por Gaspar de Texeda (Valladolid: Sebastián Martínez). Ejemplar de la Biblioteca Nacional de Madrid.

- (1553): Cosa nueva. Primero libro de cartas mensageras, en estilo Cortesano, para diuersos fines, propósitos con los títulos y cortesías que usan en todos los estados. Compuesto por Gaspar de Texeda (Valladolid: Sebastián Martínez). Ejemplar de la Biblioteca de la Hispanic Society of America.

- (1552): Segundo libro de cartas mensageras, en estilo cortesano a infinitos propósitos. Con las diferencias de cortesías y sobreescriptos que se usan. Compuesto por Gaspar de Texeda (Valladolid: Sebastián Martínez). Ejemplar de la Biblioteca de la Hispanic Society of America.

Torquemada, Antonio, (1970): Manual de escribientes, ed. M. Josefa C. de Zamora y A. Zamora Vicente, Madrid, Anejos del Boletín de la Real Academia Española, Anejo XXI.

Torras FrancÈs, Meri, (2001): Tomando cartas en el asunto. Las amistades peligrosas de las mujeres con el género epistolar, Zaragoza, Prensas Universitarias.

Villena, Enrique de, (1958): Los doze trabajos de Hércules, ed. Marguerita Monrreale, Madrid, RAE.

Violi, Patrizia, (1999): «Cartas» en Discurso y Literatura. Nuevos planteamientos sobre el análisis de los géneros literarios, ed. Teun A. Van Dijk, Madrid, Visor, 181-203.

WARD, John O., (1999): «Los comentaristas de la retórica ciceroniana en el Renacimiento», en La elocuencia en el Renacimiento, ed. James J. Murphy, Madrid, Visor Libros, 157-210.

YCIAR, Juan de, (1552): Estilo de escriuir cartas mensageras sobre diversas materias sacadas a luz por Juan de Yciar (Zaragoza, Agustín Millán). Ejemplar de la Biblioteca Nacional de Madrid. 